
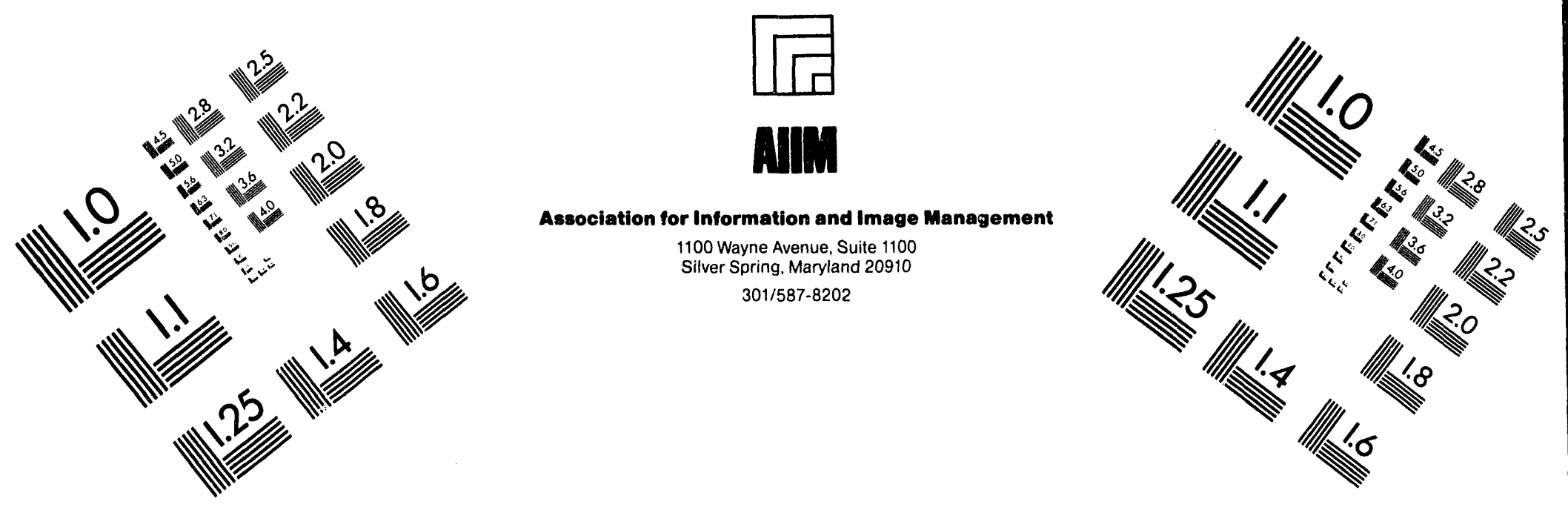

Centimeter

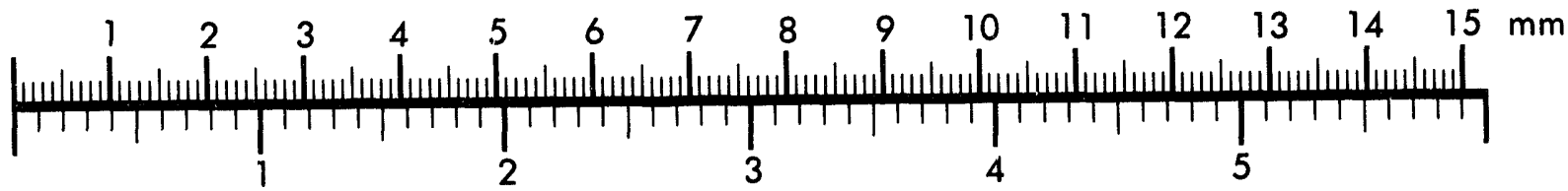
Inches
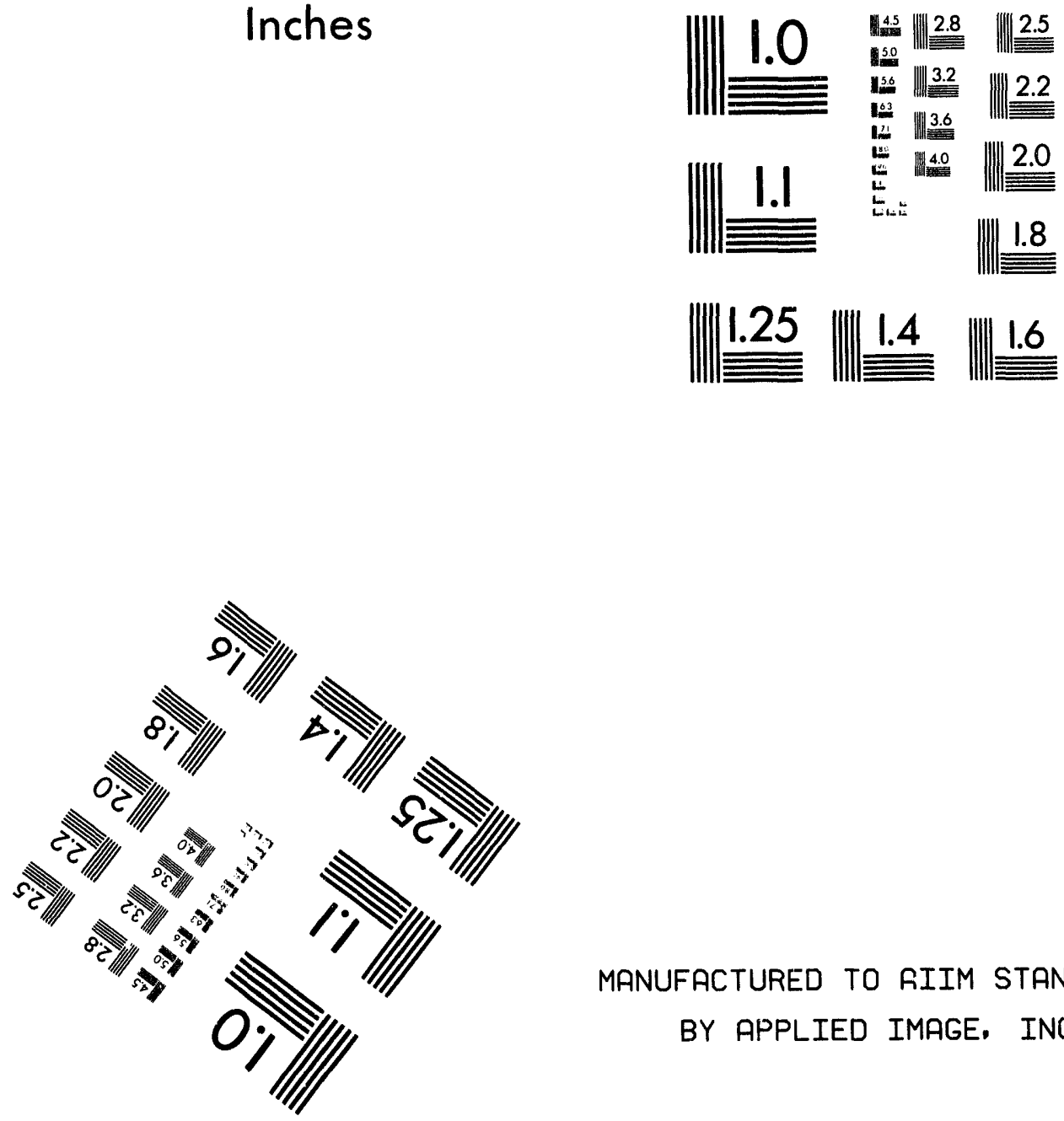

MANUFACTURED TO RIIM STANDARDS

BY APPLIED IMAGE, INC.

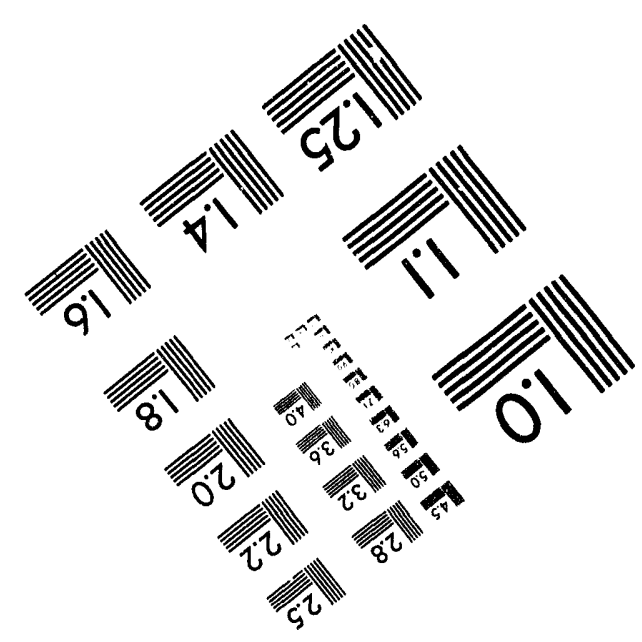



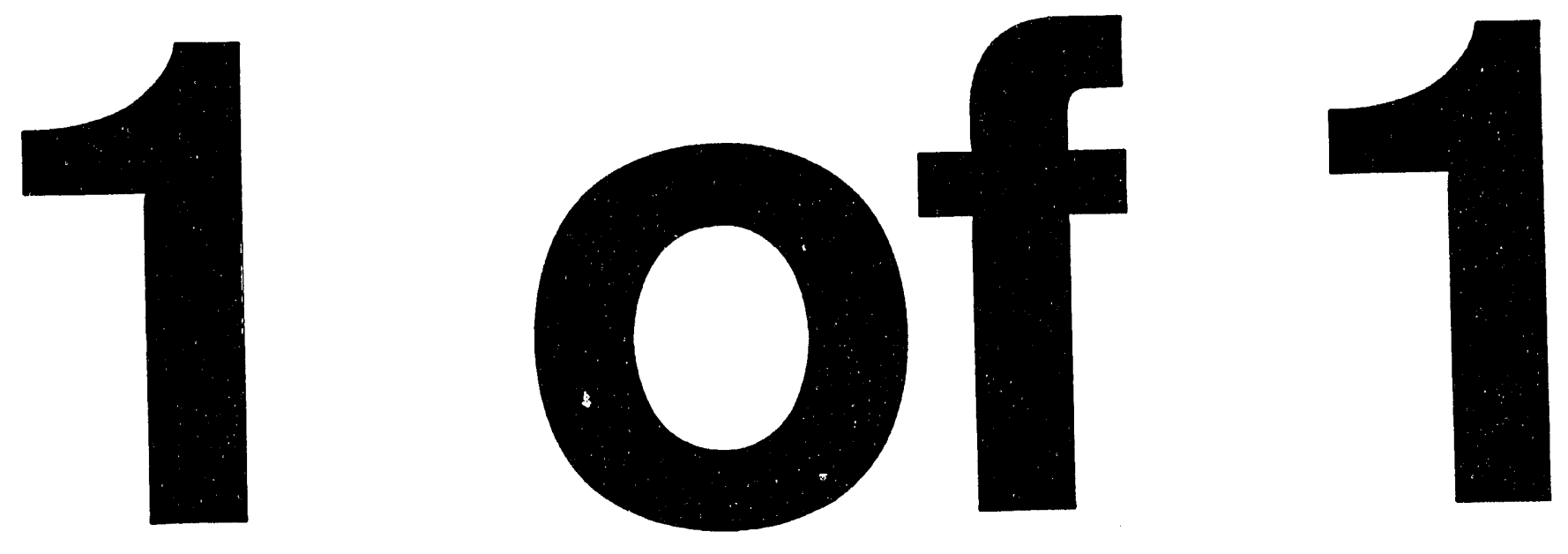
The submitted manuscript has been authored by a contractor of the U.S. Government under contract DE-AC05-84OR21400. Accordingly, the U.S. Government retains a nonexclusive, royalty tree license to publish or reproduce the published form of this contribution, or allow others to do so, for U. S . Government purposes.

\title{
EVALCATION OF PUMPING AND FUELING REQUIREMENTS FOR THE ITER EDA
}

\author{
W. A. Houlberg \\ S. E. Attenberger \\ Oak Ridge National Laboratory \\ P.O. Box 2009 \\ Oak Ridge, Tennessee 37831-8072
}

(615) $574-1350$

\section{ABSTRACT}

The relationships between fueling (gas injection and pellets of various sizes and velocities), pumping in the divertor chamber (constrained by fuel processing and divertor design), core density (constrained by the desired fusion power and helium ash accumulation), separatrix density (constrained by divertor operation and density limits) and plasma confinement models are examined for the International Engineering Tokamak Reactor (ITER) Engineering Design Activity (EDA) for guidance in the definition of design requirements for the pumping and fueling systems. Various combinations of gas and pellet injection are found to meet the constraints for operation at $1500 \mathrm{MW}$ of fusion power and $1 \mathrm{bar} \cdot 1 / \mathrm{s}\left(5.3 \times 10^{22}\right.$ atoms/s) of DT pumping. Very low pumping reduces fuel processing requirements, but can lead to excessive helium accumulation depending on the particle transport properties. Isotopic tailoring of the fuel sources, e.g., $20-30 \%$ of the input fuel stream as tritium pellets and the rest as deuterium gas, can maintain the core fuel species mixture in the optimum range for fusion production (at least a 40.60 mixture) while reducing the tritium concentration in the edge region to $20-30 \%$. This should reduce the tritium inventory in the plasma facing components. since that is typically governed by the fuel density mix near the plasma edge. A high density, low temperature ignited regime supported by deep pellet injection is shown to exist under some low confinement conditions.

\section{INTRODUCTION}

It is widely recognized that there are several constraints on the electron. plasma fuel and helium ash densities in the varions spatial regions of a tokamak fusion reactor - i.e., in the core (closed field line region), in the scrape-off laver ISOL. or open tield line region in the plasma chamber) and in the divertor chamber that should be met simultaneously for optimal performance. But because of our limited ability to quantify the physics models in extrapolations to the reactor operating domain. these constraints are not well quantified. Therefore. the particle fueling and pumping systems in ITER [1] must be designed with a reasonable amount of operational flexibility so that these constraints can be explored and performance optimized under actual operating conditions.

Although computational models of varying detail have been developed for the physics in the plasma core, SOL and divertor regions, simultaneous solution of the most sophisticated of these models in all regions has not yet been attained. The separation of the fueling and pumping problem into two primary computational regions - plasma chamber and divertor chamber provides a natural division that allows efficient solution of the coupling problem [2]. Boundary conditions at the divertor throat (the boundary between plasma and divertor chambers) define an operating domain in density-particle fiux space for each of these two spatial regions. Figure 1 illustrates, qualitatively, the solutions of the plasma chamber and divertor regions at constant fusion power. along with various constraint curves. It is the particle balance analog of the Plasma OPeration CONtour (POPCON) plots used to represent the energy balance [3]. The solution of the radial particle transport equations in the plasma chamber. with a particle Hux (net throughput) boundary condition at the divertor throat. $\Gamma_{a}$, represents the fueling side of the problem. In Fig. 1. $\Delta_{0}$ and $\Delta_{1}$ represent the density at the plasma surface resulting from shallow (gas) and deeper (pellet) fueling. respectively, at constant throughput. Operation between these curves is accessed with a combination of the two sources. The solution of the parallel transport equations in the divertor chamber, with a fixed densitv boundary condition at the divertor throat characterized by the electron density at the separatrix

*Research sponsored by the Office of Fusion Energy, U.S. Department of Energy, under contract DE-AC0584OR21400 with Martin Marietta Energy Systems, Inc. 


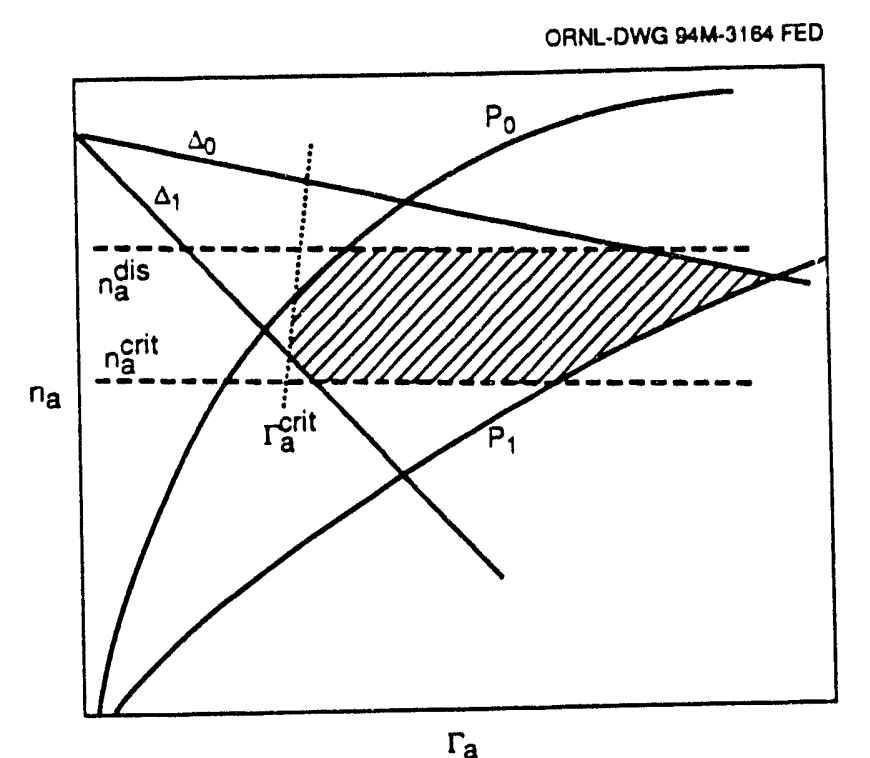

FIG. 1. A qualitative view of the operating domain for particle control in a fusion reactor at fixed fusion power. The density at the separatrix surface $\left(n_{a}\right)$ and net plasma flow across the boundary between the plasma and divertor chambers $\left(\Gamma_{a}\right)$ represent two parameters for matching the plasma chamber and divertor solutions for different fuel penetration depths $\left(\Delta_{0}<\Delta_{1}\right)$ with different levels of divertor pumping $\left(P_{0}<P_{1}\right)$. The constraints on minimum density for divertor operation $\left(n_{a}^{\text {crit }}\right)$, maximum density for density limit disruptions $\left(n_{a}^{\text {dis }}\right)$ and minimum pumping for maintaining low helium ash accumulation are also represented as constraint curves.

surface. $n_{a}$, represents the pumping side of the problem. $P_{0}$ and $P_{1}$ represent weaker and stronger pumping, respectively. The intersection of these domains is the set of parameters that can be accessed by the pumping and fueling systems simultaneously. Additional constraints on the edge density result from a minimum for acceptable divertor operation $\left(n_{a}^{\text {crit }}\right)$, and a maximum for avoiding density limit disruptions $\left(n_{a}^{\text {dis }}\right)$. A minimum on the pumping is also set by helium accumulation $\left(\Gamma_{a}^{c r i t}\right)$.

The 1-1/2-D (one-dimensional radial. plus twodimensional magnetic equilibrium time-ceperdent transport code WHIST is used to analyze the plasma chamber half of the problem. This is an extension of earlier work [2]. We expand the lower end of the pump throughput curves considered there, include an anomalous particle pinch and investigate some variations in the transport model. The details of the plasma simulation model are given in Section II. In Section III we use the above approach to quantify the relationships between pumping, fueling (pellet and gas) and edge densitv for the ITER EDA design at $1500 \mathrm{MW}$ fusion power output (see Table I). We examine helium ash accumulation in Section IV.

We also present a preliminary analysis, in Sections V and VI, of two interesting, non-standard, operating
TABLE I. ITER EDA Parameters

\begin{tabular}{llc}
\hline$R$ & Major radius & $8.11 \mathrm{~m}$ \\
$a$ & Minor radius & $3.00 \mathrm{~m}$ \\
$\kappa$ & Elongation & 1.55 \\
$\delta$ & Triangularity & 0.22 \\
$B_{t}$ & Toroidal field & $5.70 \mathrm{~T}$ \\
$I$ & Plasma current & 24 \\
$n_{\text {Be }} / n_{e}$ & Beryllium & $1.0 \%$ \\
$P_{\text {fus }}$ & Fusion power & $1500 \mathrm{MW}$ \\
$\Gamma_{D T}^{\max }$ & Max DT Pumping & $1 \mathrm{bar} \cdot 1 / \mathrm{s}$ \\
$\Gamma_{D T}^{\max }$ & Max DT Pumping & $5.3 \times 10^{22} / \mathrm{s}$ \\
$r_{p}$ & Pellet Radius & $4.25 \mathrm{~mm}$ \\
$f_{\text {pel }}$ & Max pellet rate & $2.70 \mathrm{~Hz}$ \\
\hline
\end{tabular}

modes. These tend to place moderately greater demands on the fuel injection and processing systems than standard operation, yet they appear to be accessible within the present design constraints. In Section III. 'isotopic tailoring' of the pellet and gas fueling streams is explored as a means of reducing tritium inventory in plasma facing components. In Section IV. a high density, low temperature ignited regime is examined for low confinement conditions. The characteristics of both of these modes of operation are enhanced with the deepest pellet fueling and maximum available pumping. The isotopic tailoring scheme sets the design limits on the ex-vessel fuel processing system because optimal operation is attained with the $\mathrm{D}$ and $\mathrm{T}$ streams at the maximum available isotopic separation.

\section{PLASMA MODEL}

The radial particle fluxes, $\Gamma_{\jmath}$, and conduction heat Huxes, $Q_{j}$, consist of a combination of 'full' neoclassical [4] and 'diagonal' anomalous contributions for each species $j$ inside the separatrix surface, $\rho \leq a$ :

$$
\begin{aligned}
\left(Q_{j}, \Gamma_{j}\right) & =\left(Q_{j}, \Gamma_{j}\right)^{\mathrm{neo}}+\left(Q_{j}, \Gamma_{j}\right)^{\mathrm{an}} \\
Q_{j}^{\mathrm{an}} & =-n_{j} \chi_{j}^{\mathrm{an}} \frac{\partial T_{j}}{\partial \rho} \\
\Gamma_{j}^{\mathrm{an}} & =-D_{j}^{\mathrm{an}} \frac{\partial n_{j}}{\partial \rho}+V_{j}^{\mathrm{an}} n_{j} \\
\chi_{e}^{\mathrm{an}} & =\chi_{i}^{\mathrm{an}}=D_{j}^{\mathrm{an}}=C^{\mathrm{an}} g(\rho) \\
g(\rho) & =1+4(\rho / a)^{2} \\
V_{j}^{\mathrm{an}} & =-C_{p} \frac{D_{j}^{\text {an }}}{a}\left(\frac{\rho}{a}\right)^{6}
\end{aligned}
$$

The anomalous particle pinch velocity, $V_{j}^{\mathrm{an}}$, is important only in the outer $\approx 30 \%$ of the plasma radius with $C_{p}=V_{j}^{a n} a / D_{j}^{A n}$ of order unity at the separatrix surface $(p=a)$ as deduced from particle transport analysis in many pellet injection experiments $[\dot{j}]$. The anomalous transport coefficients are normalized (through $C^{\text {an }}$ ) to match a global $\tau_{E}$ expressed as the minimum of either neo-Alcator or a multiple, $H$, of ITER L-mode continement [6]: 


$$
\begin{aligned}
& \tau_{E}=\min \left(\tau_{\mathrm{NA}}, H \times \tau_{\text {TTER }},\right. \\
& \tau_{\mathrm{NA}_{\mathrm{A}}}=0.07 \bar{n}_{e 20 \alpha} R^{2} q_{*} \\
& \eta_{*} \equiv \frac{j a B_{*}}{I_{M}}\left(\frac{u}{R} ; f(\kappa, \hat{\delta})\right. \\
& f(\kappa, \delta)=\frac{\left[1+\kappa^{2}\left(1+2 \delta^{2}\right)\right]}{2} \\
& \tau_{\text {ITER89P }}=0.048 \frac{A_{i}^{0.05} I_{M}^{0.85} R^{1.2} a^{0.3} \kappa_{i}^{0.5} n_{e 20}^{0.1} B_{t}^{02}}{P_{t o t}^{0.5}} \\
& P_{\text {tot }}(\mathrm{MW})=P_{\mathrm{OH}}+P_{\alpha}+P_{\mathrm{RF}}-P_{\mathrm{rad}}
\end{aligned}
$$

where the subscript 20 on the density designates units of $10^{20} \mathrm{~m}^{-3}\left(\bar{n}_{e 20}\right.$ is the line average and $n_{e 20}$ is the volume average), $I_{M}$ is the toroidal current in MA. and $A_{i}$ is the average atomic mass number of the ions. Neoclassical electrical resistivity is used to evolve the current profile from initial conditions to quasi steady-state (in the presence of sawtooth activity). The neoclassical bootstrap current model is from Hirshman [7].

The densities and temperatures in the SOL are determined from 1-D (radial. constant values along field lines) equations on the plasma chamber side with energy and particle sink terms representing the flows to the divertor chamber, and continuity conditions at the SOL-plasma core interface. The net DT throughput at the divertor throat is specified (i.e.. the DT pump throughput rate $\int d A_{\|} \Gamma_{\| D T}$ ). The net parallel flows (or pumping rates) of $D, T$ and He are scaled in proportion to their local densities. $\Gamma_{\| j} \propto\left(n_{j} / n_{D}+n_{T}\right) \Gamma_{\| D T}$. This approximation follows from the assumption of equal parallel flow velocities due to frictional coupling with $v_{\|} \ll v_{t h}$. The radial transport coefficients are assumed constant in the SOL. equal to their values in the plasma core at $\rho=a$.

Recycle at the chamber walls is $100 \%$ (saturated approximation) and consists of energetic (partially reflected charge-exchange neutrals and degraded in energy) and the rest cold (Franck-Condon) neutrals. The 'wall' is specified as $\bar{j} \mathrm{~cm}$ from the separatrix surface, representative of the geometry near the divertor throat. A $1 \%$ beryllium fraction is assumed in both the plasma and SOL.

\section{SEPARATRIX DENSITY}

Steady-state solutions to the transport equations are generated by the WHIST time-dependent code at the desired fusion power by utilizing feedback on the auxiliary particle sources -- either gas or pellets or a combination of the two. With $100 \%$ recrcle from the walls. the only sinks for the DT fuel are fusion ( 10 mbar. $1 / \mathrm{s}$ of each $D$ and $T$ at $1500 \mathrm{MIV}$ ) and the prescribed net How at the divertor throat. which is equal to the pump throughput when there is no auxiliary fueling in divertor chamber. We then examine the separatrix density and other plasma parameters with increasing fuel throughput. The difference between the procedure in the present calculations and the earlier work in Ref. [2] is in the use of feedback control on the fusion power, rather than imposing a very slow density ramp (which scans a range of fusion powers).

For a reference density limit we use the expression for the limit on separatrix density expressed in terms of the flux across the separatrix given by Borass [8]

$$
n_{\mathrm{B}}=1.23 \times 10^{20} Q_{\perp a}^{0.66} B_{t}^{0.33}\left[R q_{95}\right]^{0.06}
$$

where $Q_{\perp a}\left(\mathrm{MVV} / \mathrm{m}^{2}\right)$ is the heat flux conducted and convected across the flux surface defined by the separatrix, $B_{t}$ is the toroidal magnetic field, $R$ is the major radius and $q_{95}$ is the safety factor at the surface containing $95 \%$ of the toroidal flux. All units are mks unless otherwise specified. This limit is typically $n_{\mathrm{B}} \approx 0.5 \times 10^{20} \mathrm{~m}^{-3}$ for the ITER EDA design at $1500 \mathrm{MW}$.

As shown in Fig. 2a, injection of $4.25 \mathrm{~mm}$ effective spherical radius pellets in the range $0.5-3.0 \mathrm{~km} / \mathrm{s}$ maintains the separatrix density below the density limit for $\leq 1 \mathrm{bar} \cdot \mathrm{l} / \mathrm{s}$ of DT throughput. Each pellet contains $1.9 \times 10^{22}$ atoms. An injection rate of $2.75 \mathrm{~Hz}$ is required at the maximum throughput. Operation with a $\sim 50-50 \mathrm{D}-\mathrm{T}$ mixture is a result of using a $50-50 \mathrm{mix}$ in the pellet. Increasing pellet velocity increases pellet penetration and reduces the separatrix density at a constant fusion power. Increasing pump throughput also reduces the separatrix density. The separatrix density for neutral gas injection is above the value given in Eqn. (13). Therefore, a combination of gas and pellets can be used to control the separatrix densities between the respective pellet-only curves and the density limit with this selection of transport models. The expanded operating regime with deeper pellet penetration can be expressed in terms of either greater margin against the density limit. or more flexibility in the combinations of gas and pellet fueling, or in reduced pumping.

Figure $2 \mathrm{~b}$ illustrates the sensitivity to variations in the particle and energy transport properties. When the anomalous pinch term is removed $\left(C_{p}=0\right), n_{e}(a)$ increases only moderately. Reducing $D ! \chi$ by a factor of two decreases $n_{e}(u)$ by a similar amount. Increas' $g$ the energy confinement. while maintaining constant $D / \gamma$, strongly reduces $n_{e}(a)$ as seen by the $H=2$ curve. (This curve is cut off below $0.8 \mathrm{bar} \cdot 1 / \mathrm{s}$ because of helium accumulation discussed in the next section.) This reduction results from the higher operating temperature associated with improved confinement and corresponding !ower density needed to maintain constant fusion power. 


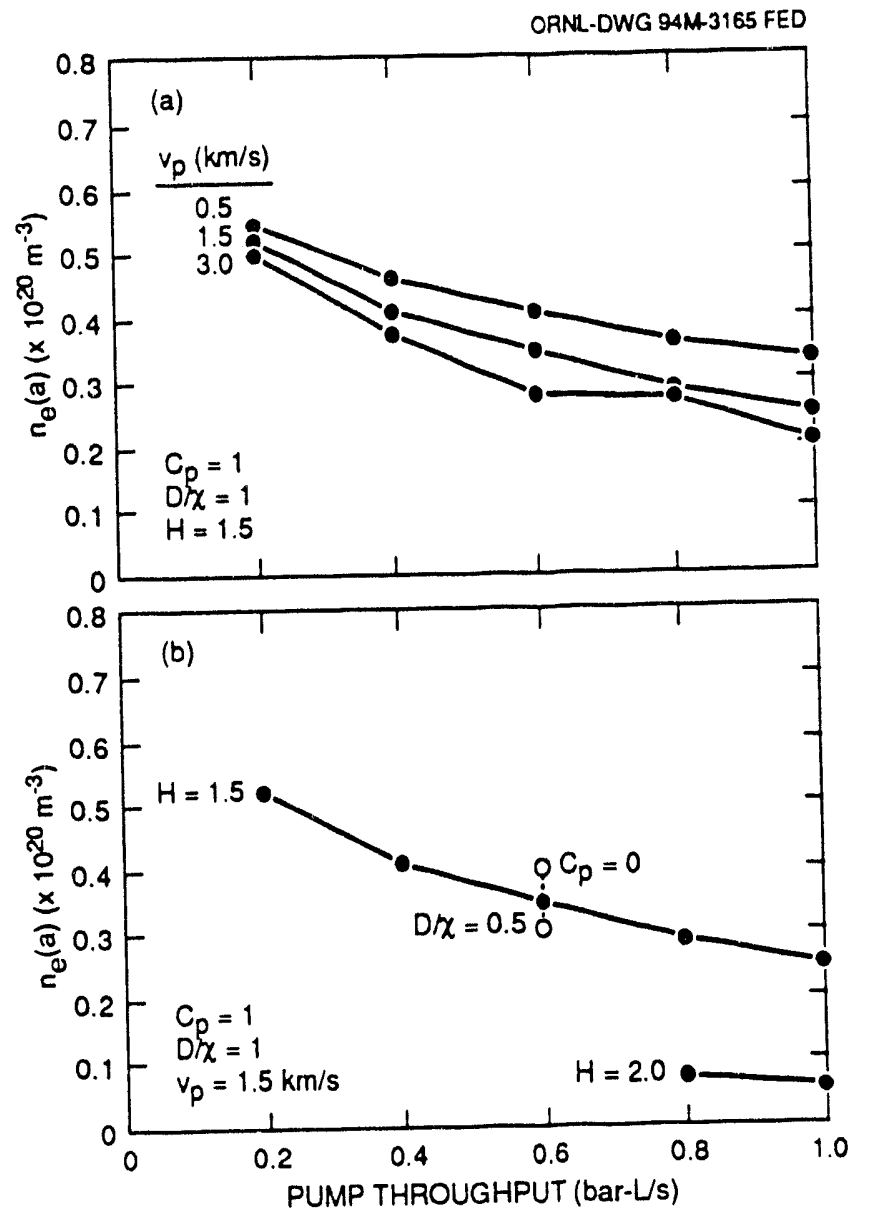

FIG. 2. The electron density at separatrix, $n_{e}(a)$, a) decreases with pump throughput and increasing fuel penetration (represented here by increasing pellet velocity), and b) decreases strongly with enhanced energy confinement. decreases weakly with reduction of $D / \chi$ and increases weakly when the particle pinch is eliminated $\left(C_{p}=0\right)$. The density when the particle pinch is is en (13) is approximately $5.5 \times 10^{19} \mathrm{~m}^{-3}$ and the gas fueling curve lies above this limit, giving an operating domain between the respective pellet fueling curves and the edge density limit.

\section{HELICM ASH ACCLMULATION}

In Fig. 3 we show the axial helium fraction for the same cases studied in Fig. 2. Variations in the pellet fueling velocity have no significant influence on the helium ash accumulation as seen in Fig. 3a. Reduced purnping (higher recycle) to $0.2 \mathrm{bar} \cdot \mathrm{l} / \mathrm{s}$ moderately increases the helium fraction for the reference model. The species dependence of the particle transport coetticient in that model is based on the assumption that helum is not preferentially accumulated as shown in the helium experiments on TEXTOR [9] and DIII-D \{10\}. Reducing $D /$, moderately increases the helium fraction, but elimination of the anomalous particle pinch has esisentially no effect as seen in Fig. 3b. However. is the

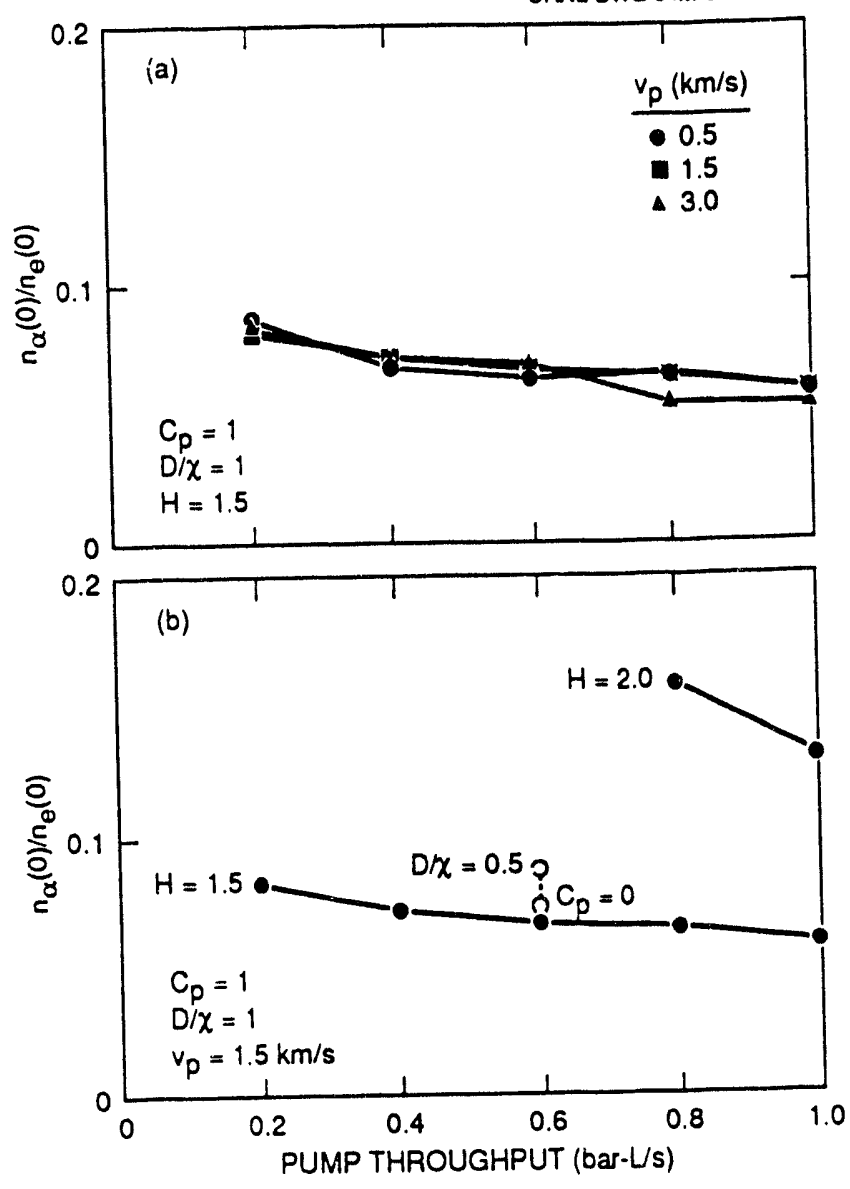

FIG. 3. The axial helium fraction a) decreases modestly with pump throughput and is essentially independent of the pellet fueling depths for the reference confinement model $(H=1.5)$, and $\mathrm{b})$ is strongly increased by improved energy confinement $(H=2)$, but moderately increased by elimination of the particle pinch or reduction of $D / \chi$. For $H=2$, helium ash accumulation is strong enough to prevent steady-state solutions at $0.6 \mathrm{bar} \cdot \mathrm{l} / \mathrm{s}$ and below.

overall confinement increases ( $H=2$ ), helium accumulation increases dramatically and does not allow a steady-state ignited solution for $\leq 0.6 \mathrm{bar} \cdot \mathrm{l} / \mathrm{s}$. In these circumstances. helium accumulation sets the minimum pumping constraint. In this case, the helium accumulation can be managed with operation at near maximum pump throughput while the edge density is increased by providing the bulk of the makeup fuel by gas injection.

\section{ISOTOPIC TAILORING}

A mixture of gas and pellet injection can provide even more Hexibility when the species mixtures of the two are varied. The differences in the depth of fueling between 
the two types of particle sources opens up the possibility of sustaining different a adial profiles of D and $T$ a concept called isotopic tailoring [11]. A rediced tritium fraction in the plasma edge region should reduce the tritium fraction incident on the plasma facing components and the vulnerable tritium inventory inside the vacuurn vessel. In addition to the safety benchits, this also has financial benetits. Reduction of the overall DT mixture to $60-40$ provides some decrease in the tritium concentration evervwhere in the plasma without hurting the fusion power density significantly. Tritium-rich pellets can be used to fuel the core and control the fusion production rate. while the plasma edge density is sustained by deuterium gas fueling.

In Fig. 4a we scan a range of D gas fueling supplemented by T-rich pellets $\left(90 \%, \mathrm{~T}, r_{p}=4.25 \mathrm{~mm}\right.$ at $1.5 \mathrm{~km} / \mathrm{s}$ with constant total fuel throughput and fusion power of $1500 \mathrm{MW}$ ) to show that the axial tritium fraction $\left(f_{T} \equiv n_{T} / n_{D}+n_{T}\right)$ can be nearly twice the edge fraction. At $0.75 \mathrm{bar} \cdot 1 / \mathrm{s} \mathrm{D}$ gas input the axial fraction is $38 \%$ and the edge fraction is $23 \%$. These conditions should reduce the tritium wall inventory by more than a factor of two from the reference $50-i 50$ DT operation. When pellet penetration depth is increased. as shown in Fig. 4b, the separation between axial and edge fractions increases. These three cases were generated with pellet effective spherical radii (mm), velocities (kmis/. and injection frequencies $(\mathrm{Hz})$ representative of what mav be expected from centrifugal accelerators (3.0.1.0.2.0). single-stage light gas guns $(4,25.1 .5 .0 .7)$ and two-stage light gas guns without sabots $(5.35 .3 .0 .0 .4)$. respectively. The impact of isotopic tailoring on the design of the fueling and ex-ressel fuel processing systems. tritium inventory, safety. and other engineering design and operational aspects are presently under evaluation [11!.

\section{LOW CONFINE.MENT OPERATION}

A high-density. low-temperature operating regime was found with low $H$-factors (L-mode like conditions) in the course of these fueling and pumping evaluations $[12\}$. The right side of the ignition curve moves to successively lower temperatures (Fig. j) as $H$ is reduced. These cases are similar to the low- $T$. high-n cases generated for ITER with the PRETOR cocie using a beta-induced reduction in continement at high densities 11 . The low temperatures allow deeper penetration of the pellets. Pellets with velocities of $35 \mathrm{~km}$ s penetrate as much as $70 \%$ of the distance to the axis with the axial temperatures below $20 \mathrm{keV}$ for the $H=1$ case. The resulting peaked lensity profiles enfance fusion production while maintaining separatrix lensities below the density limit. The normalized beta for $1500 \mathrm{MW}$ and $H=1$ is $3_{\mathrm{V}} \approx 1.5$. lower than tor higner $H$-factors. With such high densities and low
ORNL-DWG 94M-3167 FED
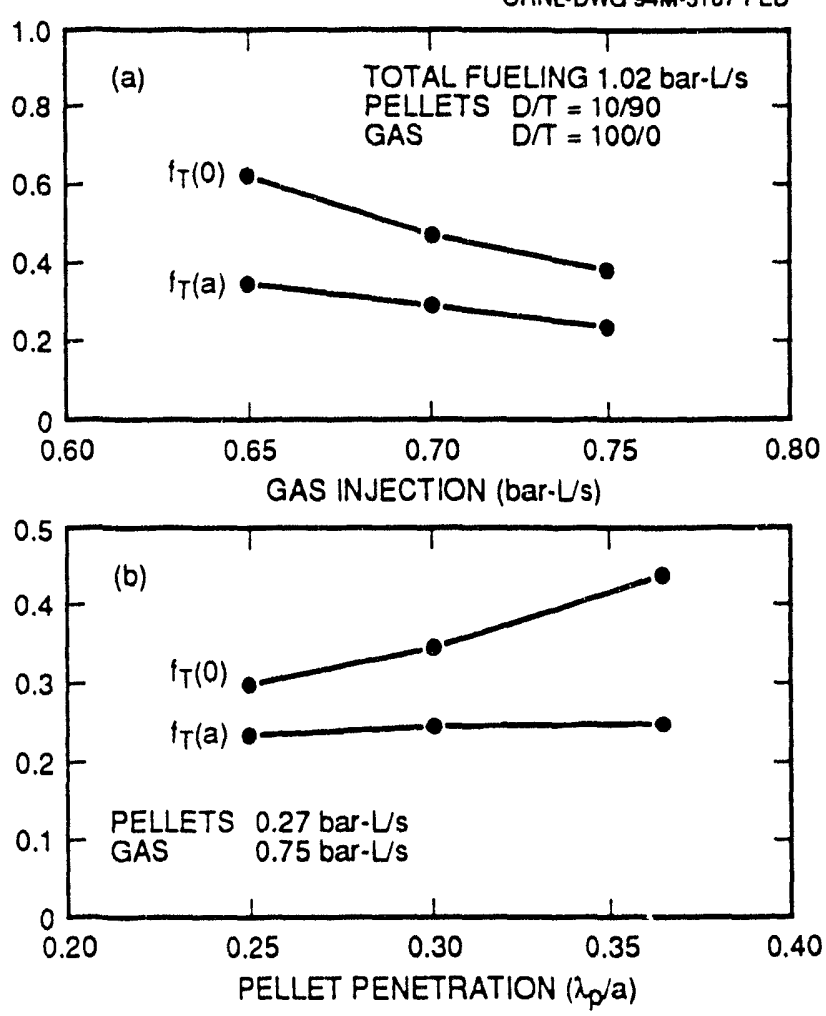

FIG. 4. The axial and edge tritium fractions a) decrease when the $D$ gas input is increased with fixed total external fuel input and the axial concentration of $\mathrm{T}$ remains about $50 \%$ higher than the edge concentration. and $\mathrm{b}$ ) the axial tritium fraction increases with pellet penetration for a fixed $D$ gas feed rate while the edge concentration is essentially constant and reflects the overall fuel input mixture.

temperatures. much of the power is radiated from the inside the separatrix $(\approx 50 \%)$. The plasma collisionality at the separatrix is above unity and the plasma mav therefore remain in L-mode for the $H=1$ case. This provides attractive divertor operating conditions. Also. the high densities and low temperatures accelerate thermalization of fast alphas, so these plasmas are not very susceptible to deleterious alpha particle instabilities. However, the strong central heating by alphas, combined with radiative cooling in the outer plasma, tends to constrict the temperature and. therefore. the inductively driven current density protile. This generates strong sawtooth activity and fusion power oscillations. The low temperature also generates strong resistive magnetic flux consumption ( lioop $\approx 0.4 \mathrm{~V}$ ) that limits the duration of this operating mode. Attempts to connect the ignition curves to the Ohmic operating curve without anxiliary heating have been unsuccessful for these ITER simulations hecause the Ohmic curve tends to termmate in a radiative collapse as the density is raised. 


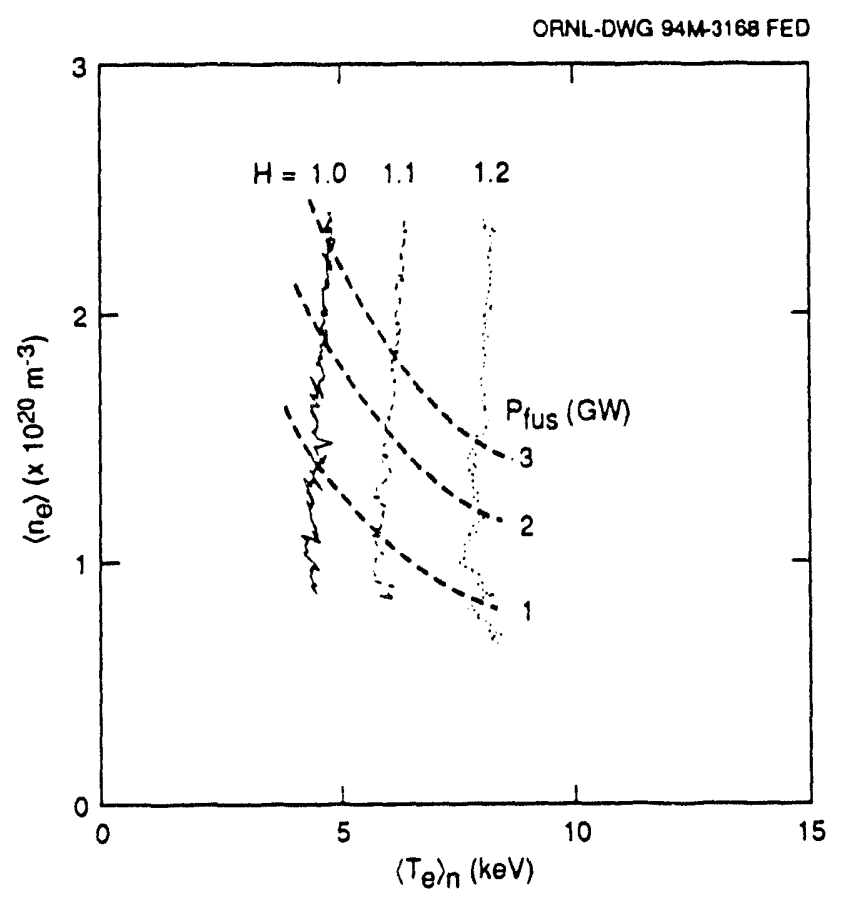

FIG. 5. Stable ignited thermal equilibrium contours $\left(P_{\text {aux }}=0\right)$ are pushed to very low temperatures for low $H$-factors of 1.0 .1 .1 , and 1.2 . The raggedness of the contours are the result of sawtooth activity during the slow density ramp used to generate the curves with a time-deperident simulation.

\section{SLMMARY}

Manv aspects of particle control in ITER have been examined here. The most definitive conclusion that can be reached from these studies is that Hexible fueling and pumping systems enhance the probability of ITER meeting the various constraints on fusion power production and plasma edge densities. while minimizing invessel tritium inventory and helium ash accumulation. At the same time, we must recognize the uncertainties in extrapolating our limited knowledge of particle control to ITER conditions. The particle transport models will undoubtedly mature as the data from the present generation of long pulse divertor experiments is generated. The combination of two fueling schemes with different penetration depths. as provided by gas and pellets, should provide the Hexibility to cover these uncertainties. The isotopic tailoring concept bears much promise from a safety standpoint. and is only possible with more than one fueling system. Deep pellet penetration can provide an interesting alternative operating mode in the event confinement is poor.

\section{ACKNOWLEDGEMENTS}

This research was sponsored by the Office of Fusion Energy, U.S. Department of Energy, under contract DEAC05-84OR21400 with Martin Marietta Energy Systems, Inc.

\section{REFERENCES}

1) "ITER Outline Design Report," presented by the ITER Director. ITER TAC-4 Report, Vol. I (1994).

2] W.A. Houlberg, S.E. Attenberger. MI.J. Grapperhaus. "Density Profile Control in a Fusion Reactor Using Pellet Injection." Nucl. Fusion, in press.

3) W.A. Houlberg, S.E. Attenberger. L.M. Hively, Nucl. Fusion 32 (1982) 935

4) F.L. Hinton. R.D. Hazeitine, Rev. .Yodern Phys. 48 (1976) 239.

5) S.L. Milora. W.A. Houlberg, L.L. Lengyel, V. Mertens "Review of Pellet Fuelling," Nucl. Fusion. in press.

6) N.A. Uckan. P.N. Yushmanov, T. Takizuka, et al.. in Plasma Physics and Controlled Nuclear Fusion Research 1990 (Proc. 13th Int. Conf. Washington. DC. 1990), Vol. 3. IAEA. Vienna (1991) 307.

7) S.P. Hirshman. Phys. Fluids 31 (1988) 3150.

(8) K. Borrass. D. Campbell, S. Clement. G. Vlases. "Scrape-Off Layer Based Modeling of the Density Limit." Joint European Torus Report JET-P(92)44 (1992).

(9) D.L. Hillis. K.H. Finken. J.T. Hogan. K.H. Dippel, R.A. Moyer, et al.. Phys. Rev. Lett. 65 ; 1990) 2382.

(10) D.L. Hillis. M.R. Wade. J.T. Hogan. IV.P. West. K.H. Burrell, et al.. "Helium Transport and Exhaust Studies of H-mode Discharges in the DIII-D Tokamak." Plasma Phvs. Cont. Fusion. in press.

11] M.J. Gouge. et al.. "Fuel Source Isotopic Tailoring and its Impact on ITER Design, Operation and Safety." in preparation.

$12 \mid$ D.R. Mikkelsen. K.M. McGuire. G.L. Schmidt. S.J. Zweben. S.E. Attenberger, W.A. Houiberg. S.L. Milora. "Core Fueling to Produce Peaked Densitv Profiles in Large Tokamaks." submitted to Nuci. Fusion.

\section{DISCLAIMER}

This report was prepared as an account of work sponsored by an agency of the United States Government. Neither the United States Government nor any agency thereof, nor any of their employees, makes any warranty, express or implied, or assumes any legal liability or responsibility for the accuracy, completeness, or usefulness of any information, apparatus, product, or process disclosed, or represents that its use would not infringe privately owned rights. Reference herein to any specific commercial product, process, or service by trade name, trademark, manufacturer, or otherwise does not necessarily constitute or imply its endorsement, recommendation, or favoring by the United States Government or any agency thereof. The views and opinions of authors expressed herein do not necessarily state or reflect those of the United States Government or any agency thereof. 
The submitted manuscript has been authored by a

contractor of the U.S. Government under contract

DE.AC05.84OR21400. Accordingly, the U.S

Government relains a nonexclusive, royally the

license 10 publish of reproduce the published form

this contribution, or allow others to do so, for U. S

Government purposes.

\title{
Evaluation of Pumping and Fueling Requirements for the ITER EDA*
}

\author{
W. A. Houlberg \\ S. E. Attenberger \\ ORNL
}

\author{
ANS 11th Topical Meeting \\ on the Technology of Fusion Energy \\ New Orleans, LA \\ June 19-23, 1994
}

* Research sponsored by the Office of Fusion Energy, U.S.Department of Energy, under contract
DE-AC05-84OR21400 with Martin Marletta Energy Systems, Inc. 


\section{Outline}

\section{Particle Control Objectives}

Plasma Model

\section{ITER Applications:}

- Separatrix Density

- Helium Ash Accumulation

- Isotopic Tailoring

- Low Confinement Operation

\section{Summary}




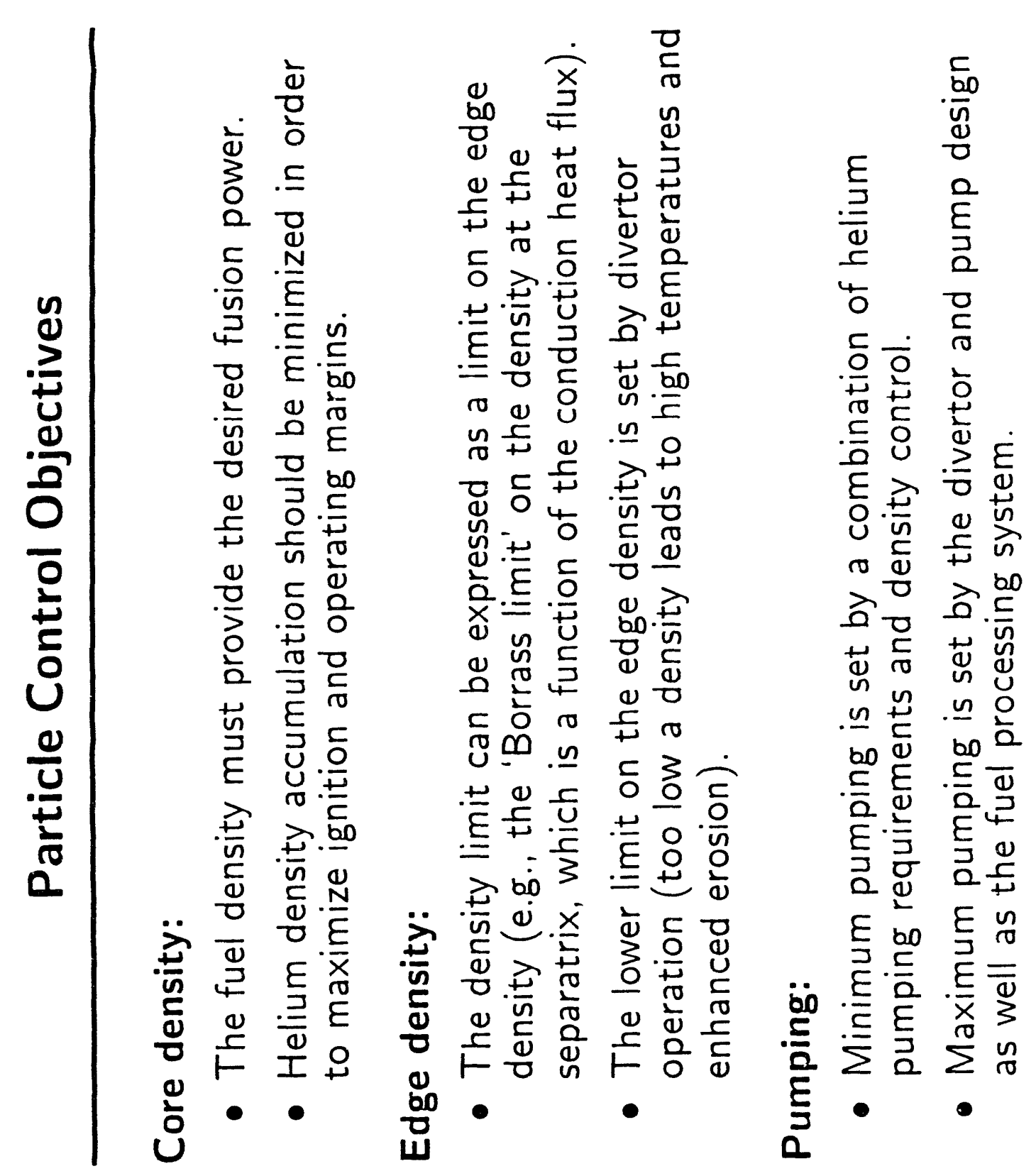




\section{Computational Region and BCs}

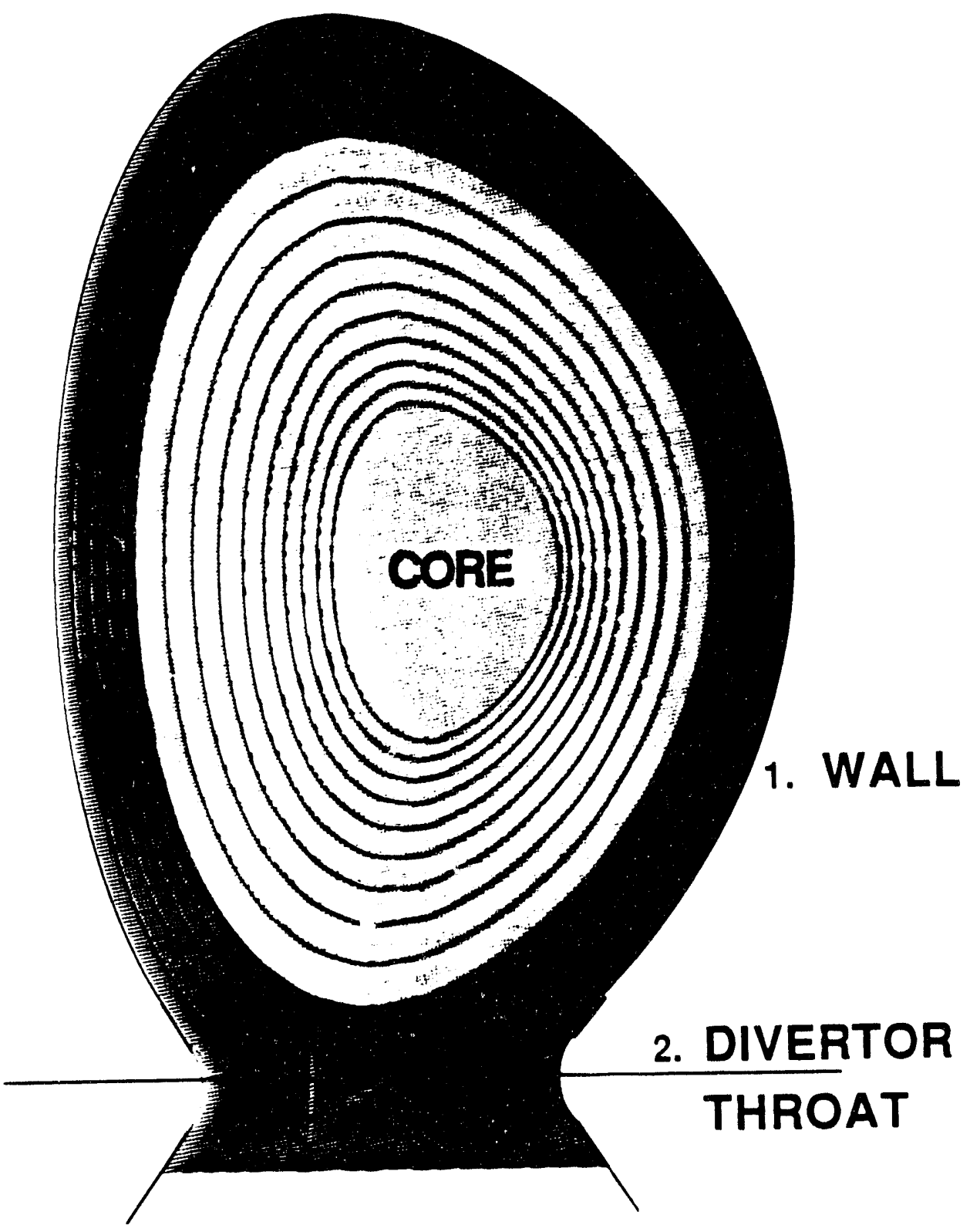

1. Wall - $100 \%$ recycle.

2. Divertor Throat - net DT throughput specified; net He flux is proportional to the He fraction and net DT flux. 


\section{Transport Model}

Core:

$$
\begin{aligned}
\left(Q_{j}, \Gamma_{j}\right) & =\left(Q_{j}, \Gamma_{j}\right)^{\text {neo }}+\left(Q_{j}, \Gamma_{j}\right)^{\text {an }} \\
\chi_{e}^{\text {an }} & =\chi_{i}^{\text {an }}=D_{j}^{\text {an }}=C^{\text {an }} g(\rho) \\
g(\rho) & =1+4(\rho / a)^{2} \\
\tau_{E} & =\min \left(\tau_{E}^{\text {NA }}, H \tau_{\text {ITER } 89 P}\right) \\
V_{j}^{\text {an }} & =-C_{p} \frac{D_{j}^{\text {an }}}{a}\left(\frac{\rho}{a}\right)^{6}
\end{aligned}
$$

- Full neoclassical plus anomalous particle and thermal fluxes.

- $D_{j}^{\text {an }} / \chi_{e}^{\text {an }}$ is unity in the reference cases, representing a typical (but widely varying) value observed in DIII-D He pumping experiments.

- Transport coefficients are normalized (through $C^{\text {an }}$ ) to match a global $\tau_{E}$ expressed as a multiple ( $H$-factor) of L-mode confinement.

- Anomalous diffusivities have a parabolic radial form factor, $g(\rho)$.

- The normalized pinch $\left(a V_{j}^{\mathrm{an}} / D_{j}^{\mathrm{an}}\right)$ is species independent, thus satisfying $C_{v}=1$ as observed in DIII-D He pumping experiments.

\section{Scrape-off layer:}

$$
\chi(\rho>a) \cdot D(\rho>a)=\chi(a) \cdot D(a)
$$

- Radially constant particle and thermal diffusivities are matched to the core values at the separatrix (but no pinch in the SOL). 


\section{ITER Application}

ITER EDA Parameters

\begin{tabular}{lll}
\hline$R(\mathrm{~m})$ & Major radius & 8.11 \\
$a(\mathrm{~m})$ & Minor radius & 3.00 \\
$\kappa$ & Elongation & 1.55 \\
$\delta$ & Triangularity & 0.22 \\
$B_{t}(\mathrm{~T})$ & Toroidal field & 5.70 \\
$I(\mathrm{MA})$ & Plasma current & 24 \\
$n_{\mathrm{Be}} / n_{e}(\%)$ & Beryllium & 1.0 \\
$P_{\text {fus }}(\mathrm{MW})$ & Fusion power & 1500 \\
$\Gamma_{D T}^{\max }($ bar $\mathrm{l} / \mathrm{s})$ & Max DT Pumping 1 \\
$\Gamma_{D T}^{\max }(/ \mathrm{s})$ & Max DT Pumping $5.3 \times 10^{22}$ \\
$r_{p}(\mathrm{~mm})$ & Pellet Radius & 4.25 \\
$f_{\text {pel }}(\mathrm{Hz})$ & Max pellet rate & 2.70 \\
\hline
\end{tabular}

Borrass density limit from TAC-4 (at separatrix):

$$
\begin{aligned}
n_{\mathrm{B}}\left(\mathrm{m}^{-3}\right) & =1.23 \times 10^{20} Q_{\perp a}^{0.66}\left(\mathrm{MW} / \mathrm{m}^{2}\right) B_{t}^{0.33}(\mathrm{~T})\left[R(\mathrm{~m}) q_{95}\right]^{0.06} \\
& \approx 5.5 \times 10^{19} \mathrm{~m}^{-3}
\end{aligned}
$$




\section{Separatrix Density, $H=1.5$}

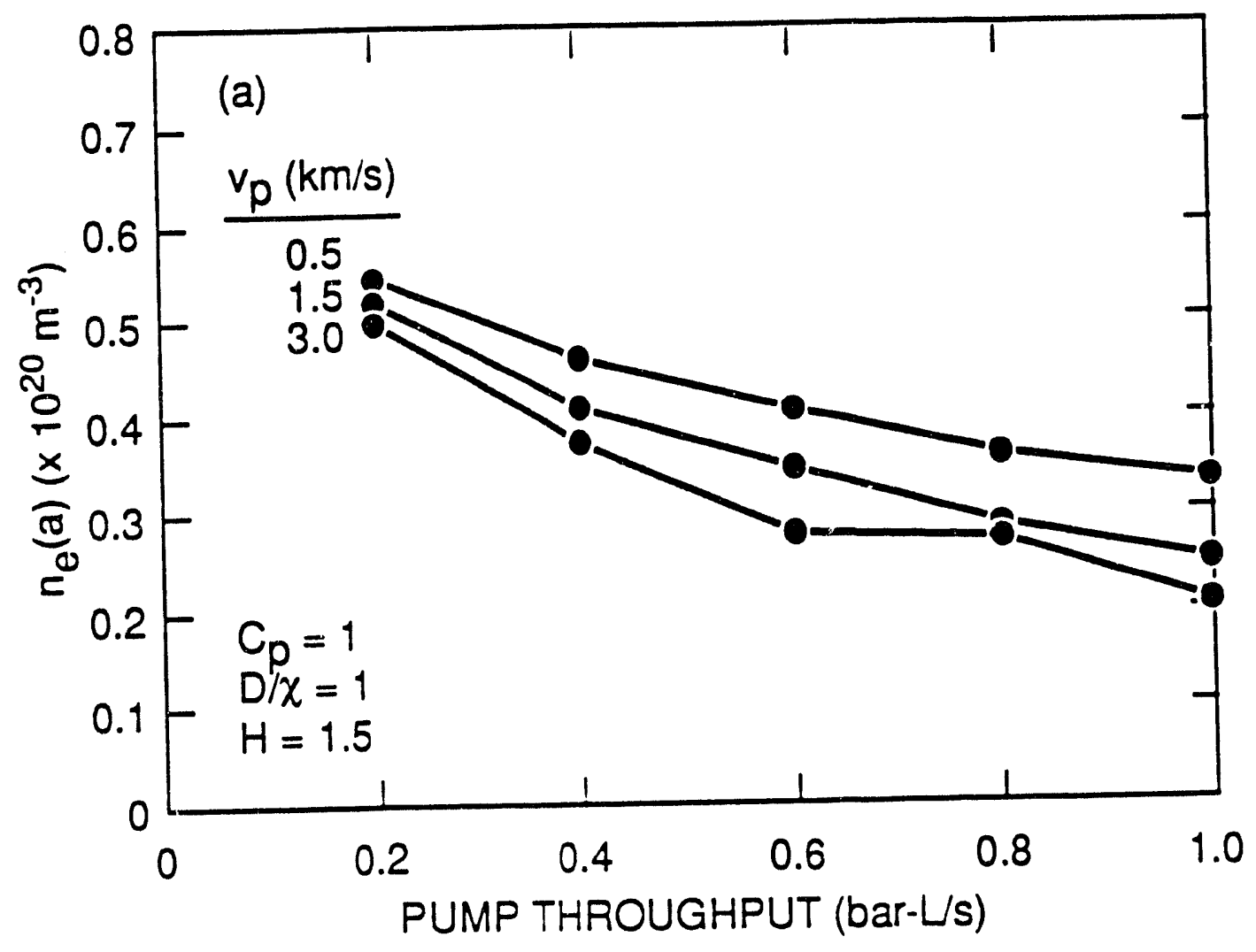

- The separatrix density decreases with DT pump throughput and increasing pellet velocity (fuel penetration).

- The gas fueling curve lies above the pellet fueling and 'Borrass' limit curves so gas can be added to raise the separatrix density at a given pump throughput. 


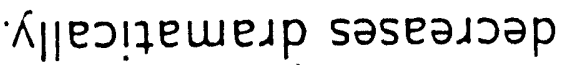

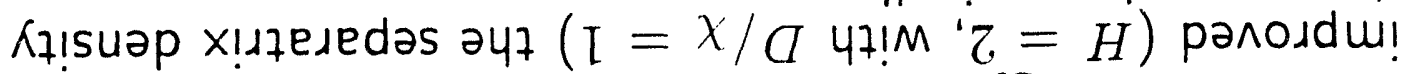

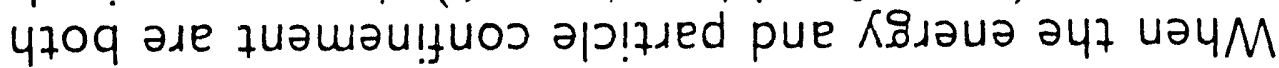

s/1.1eq 9.0

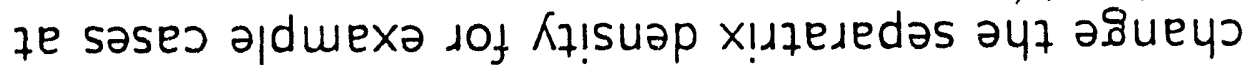

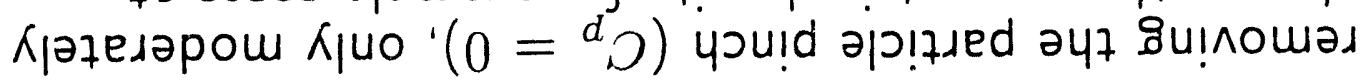

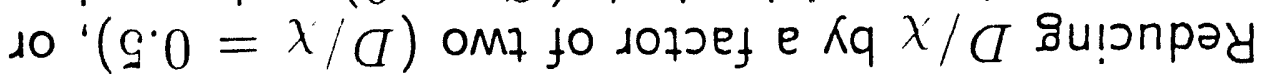

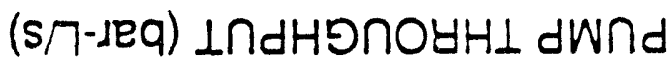

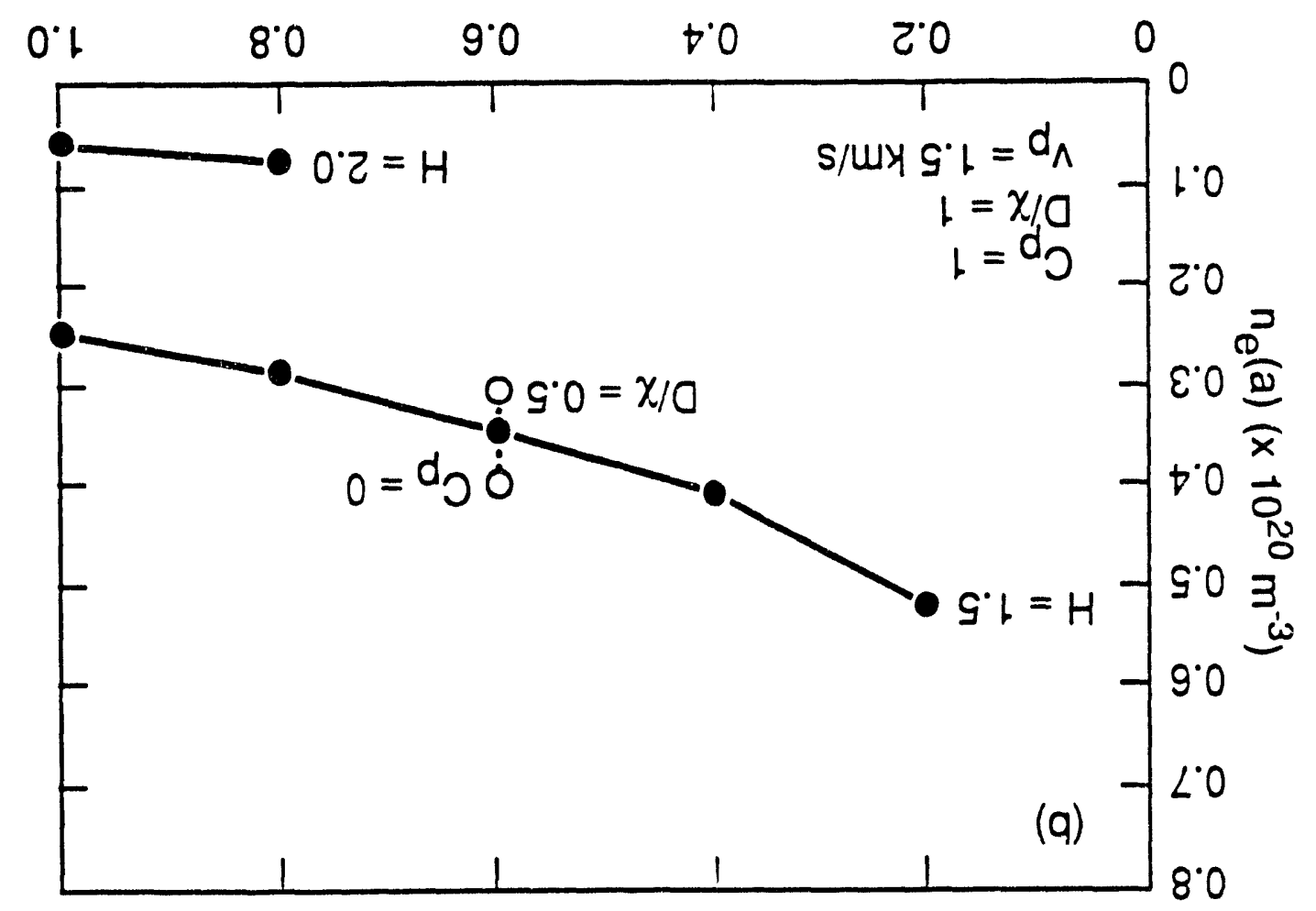




\section{Axial Helium Fraction, $\mathrm{H}=1.5$}

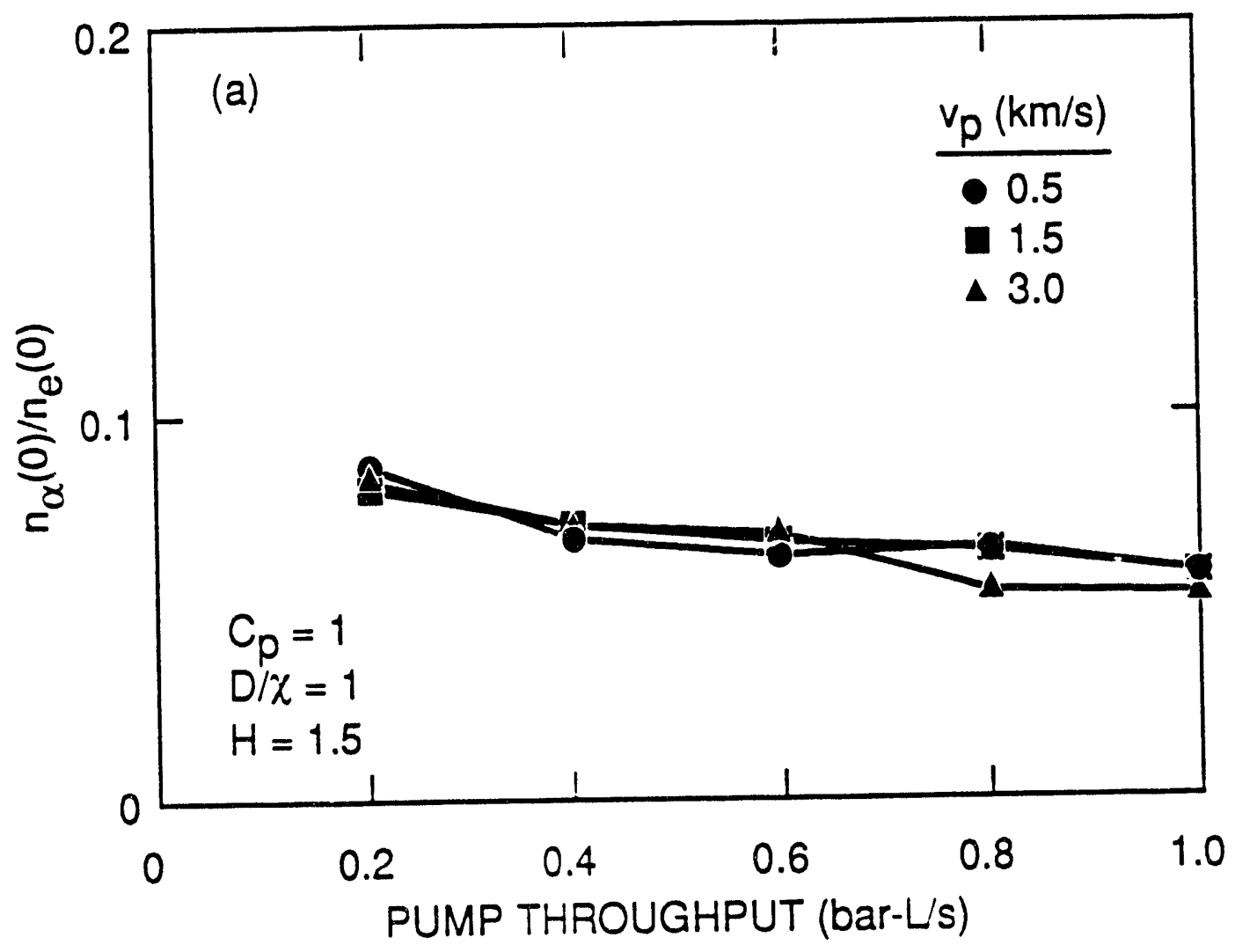

- The axial helium fraction is not significantly affected by pellet penetration over the range considered.

- Very low pumping ( 0.2 bar. $1 / \mathrm{s}$ ) leads to only $\approx 8 \%$ helium fraction. 


\section{Axial Helium Fraction, Improved Confinement}

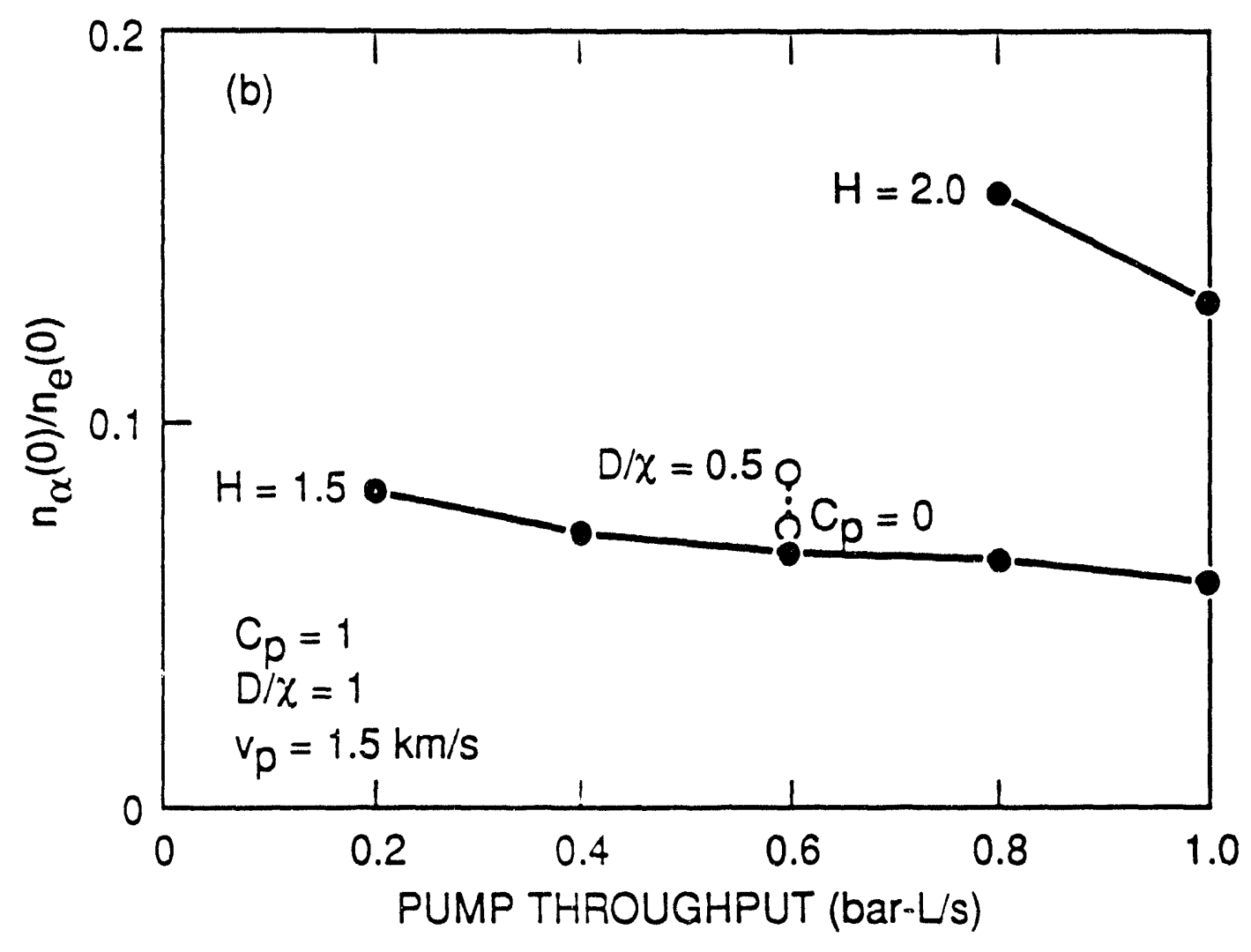

- The helium fraction on axis is most sensitive to simultaneous improvements in energy and particle confinement.

- The plasma quenches from He accumulation for DT throughput $\leq 0.6$ bar.l/s when $H=2$. 


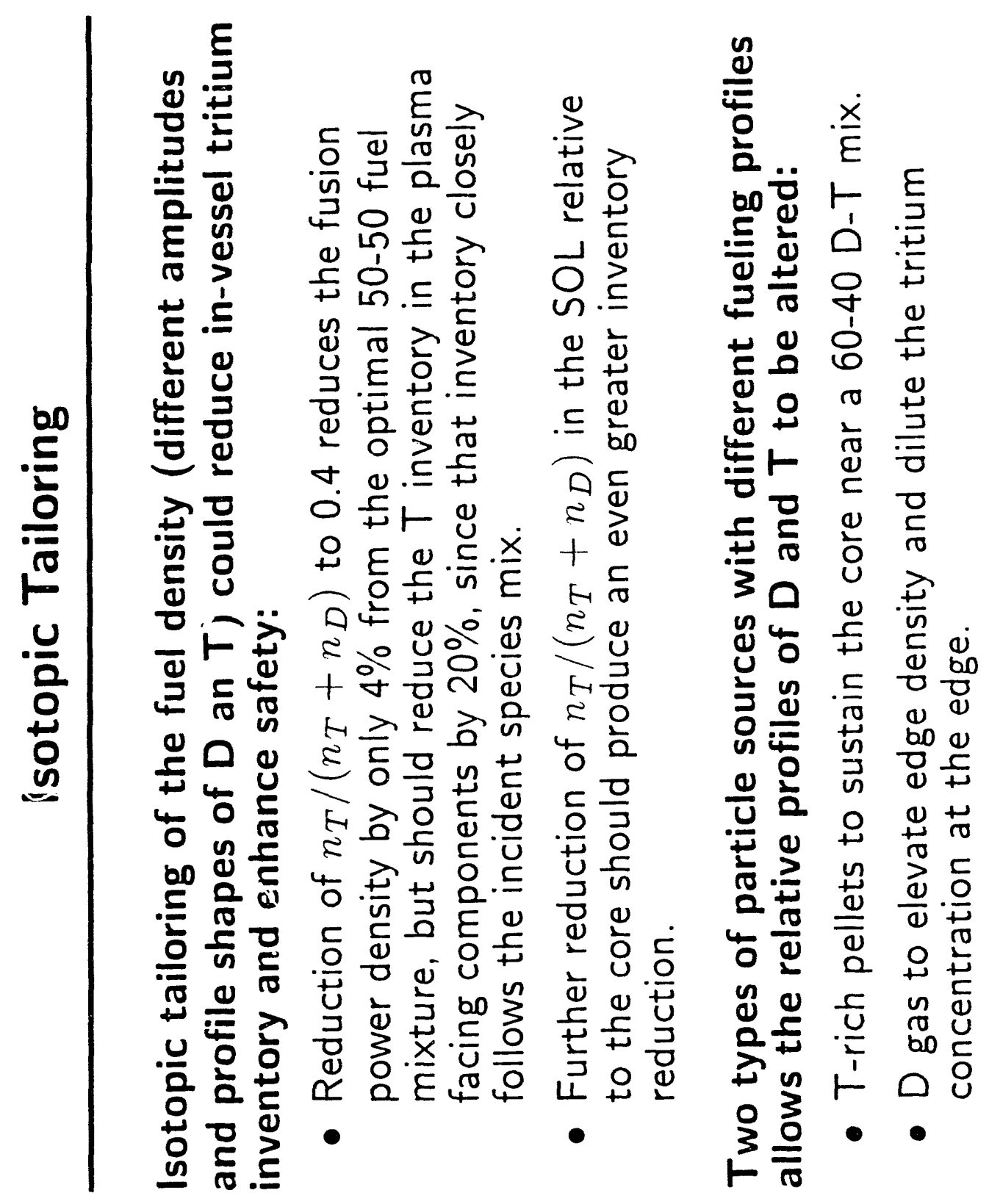




\section{Isotopic Tailoring}

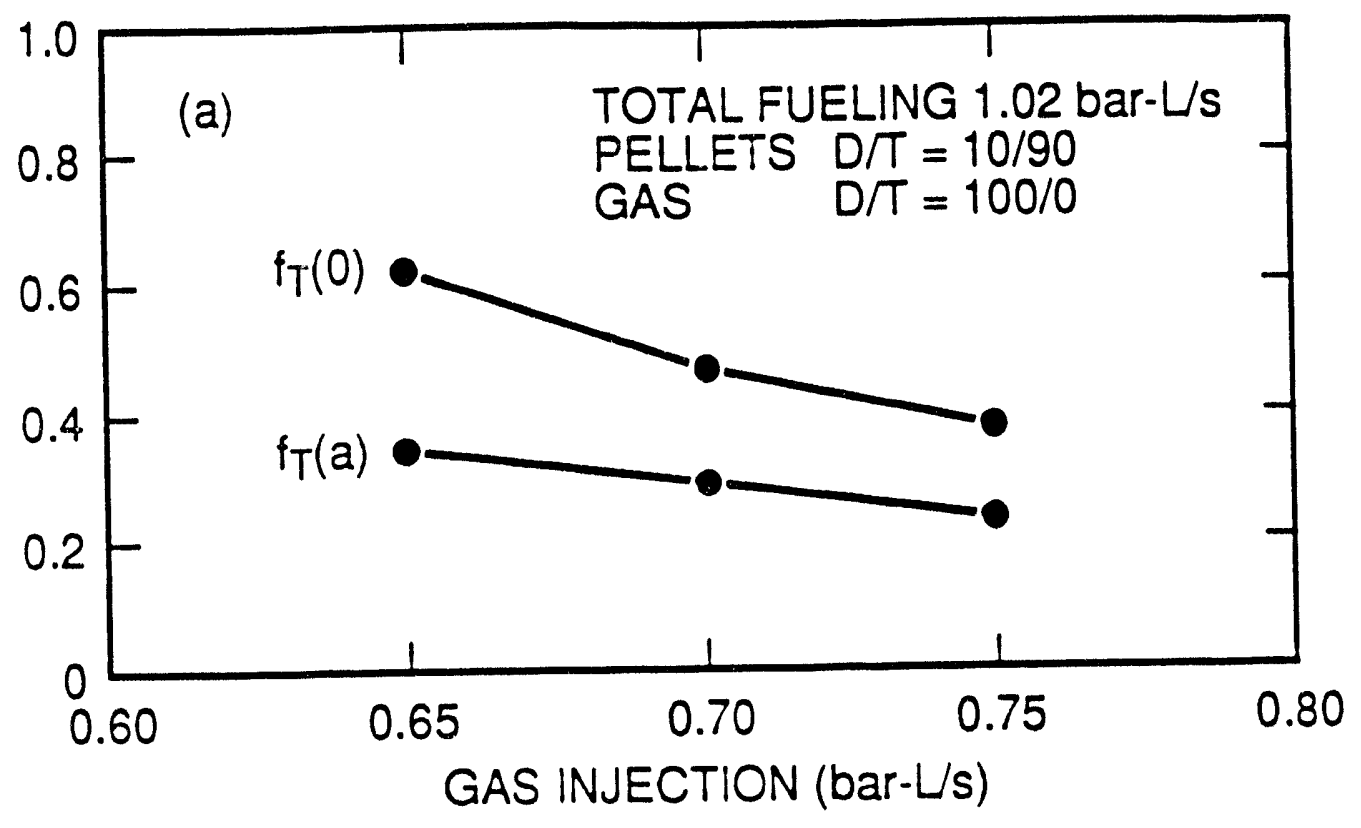

- All cases have $H=1.5,1500 \mathrm{MW}$ and $1 \mathrm{bar} \cdot \mathrm{l} / \mathrm{s}$ pumping, with T-rich pellets of $r_{p}=4.25 \mathrm{~mm}$ injected at $1.5 \mathrm{~km} / \mathrm{s}$.

- When the gas component is increased to $75 \%$ of the total fueling, the axial tritium fraction is maintained at $38 \%$ while the fraction at the separatrix is $23 \%$. 


\section{Isotopic Tailoring}

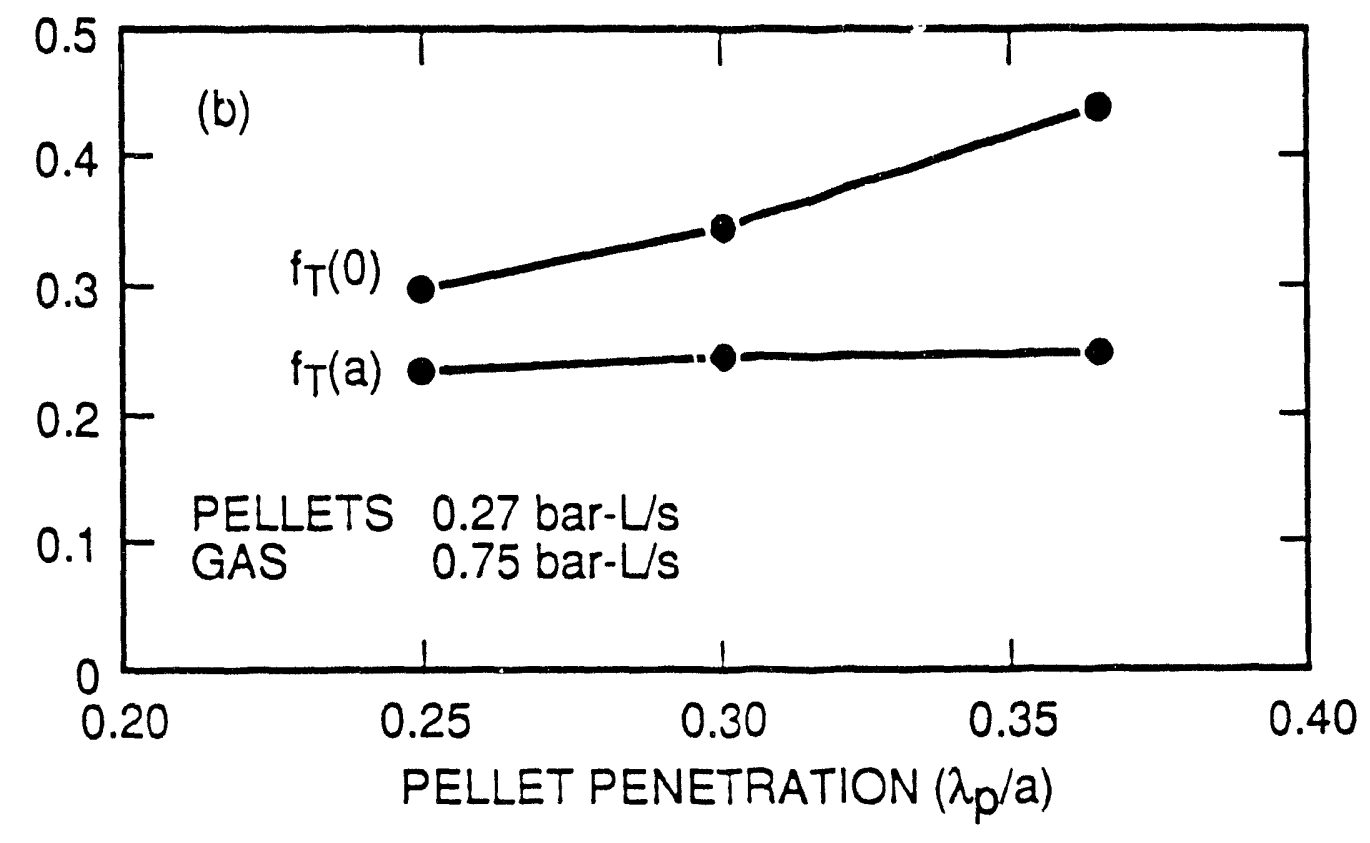

- Deeper pellet penetration from larger and/or faster pellets enhances the profile variation of the tritium fraction. 


\section{Low Confinement Operation}

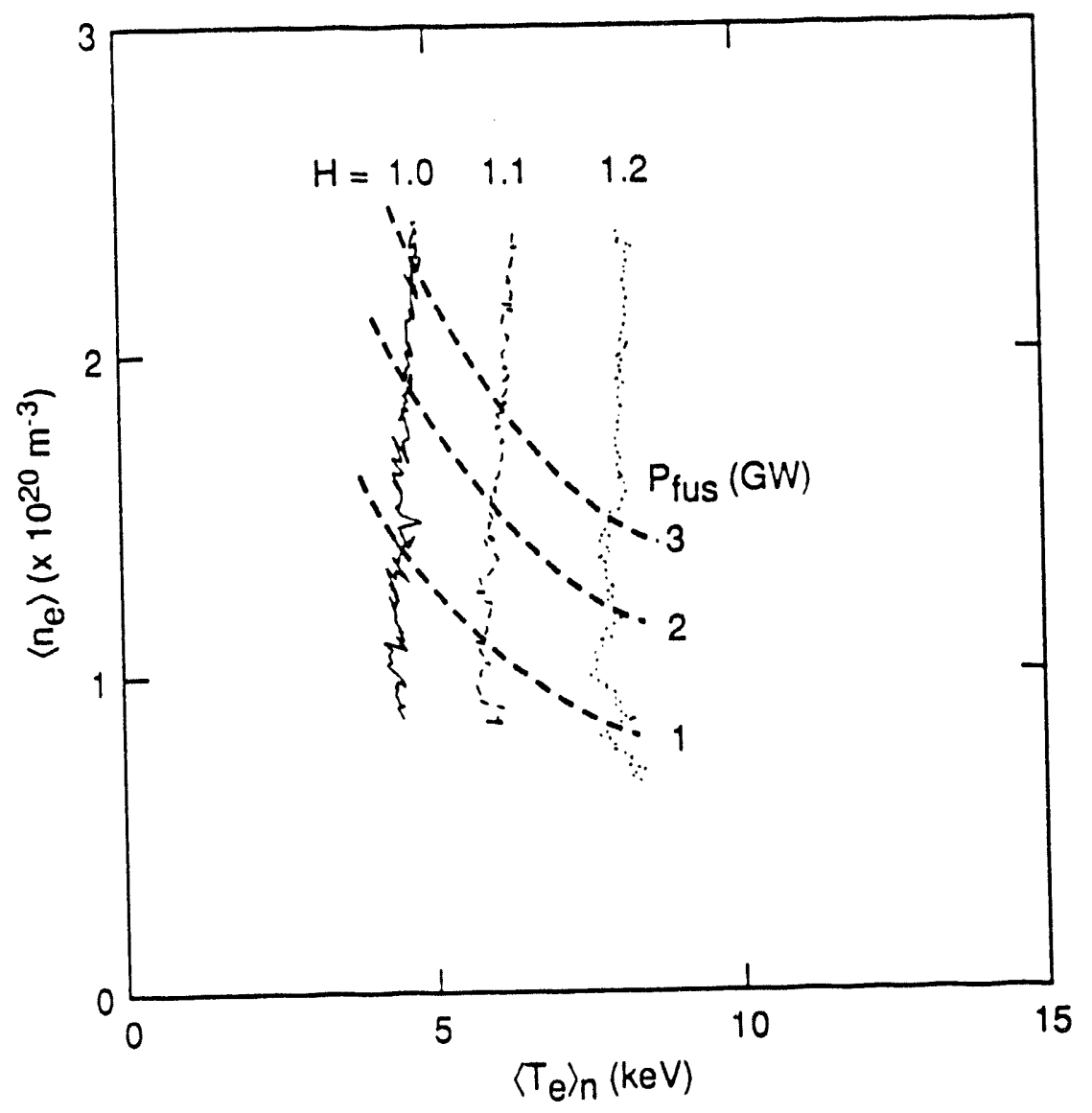

- The thermally stable branch of the ignited operating contour is pushed to very low temperatures as $H \rightarrow 1$, while peaked density profiles from deep pellet penetration allow high power operation.

- Advantages: low- $\beta_{N}$, high core radiation fraction $\approx 50 \%$ (lower divertor heat load), and low fast and thermal helium fractions.

- Disadvantages: strong sawtooth activity (raggedness in operating contours from time-dependent simulation), and high loop voltages $(\approx 0.4 \mathrm{~V})$. 


\section{Summary}

A modeling analysis has been developed that:

- Quantifies the fueling parameters and pump throughput needed to simultaneously meet core and edge density constraints for a range of transport conditions.

Non-standard operating modes:

- Fuel species isotopic tailoring using a combination of pellet and gas injection is an attractive method to reduce in-vessel $T$ inventory.

- Under L-mode like confinement conditions, low temperature, high density operation supported by deep pellet penetration may be an attractive operating mode.

A combination of gas and pellet injection enhances the range of operating scenarios for ITER, within the pumping and fueling guidelines. 

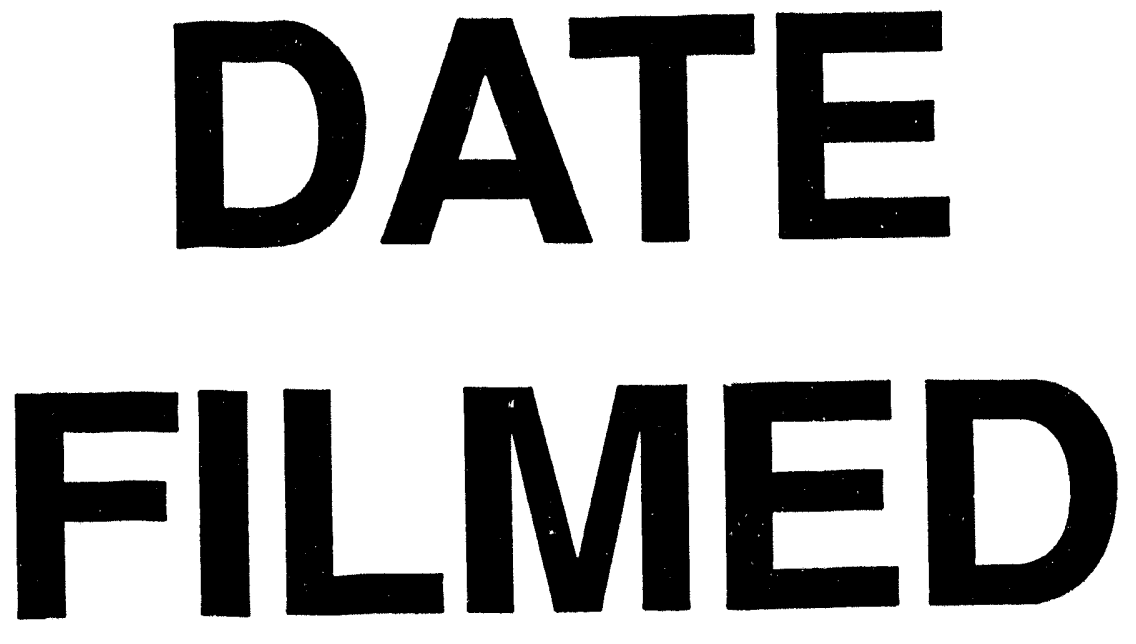

$9 / 30 / 94$
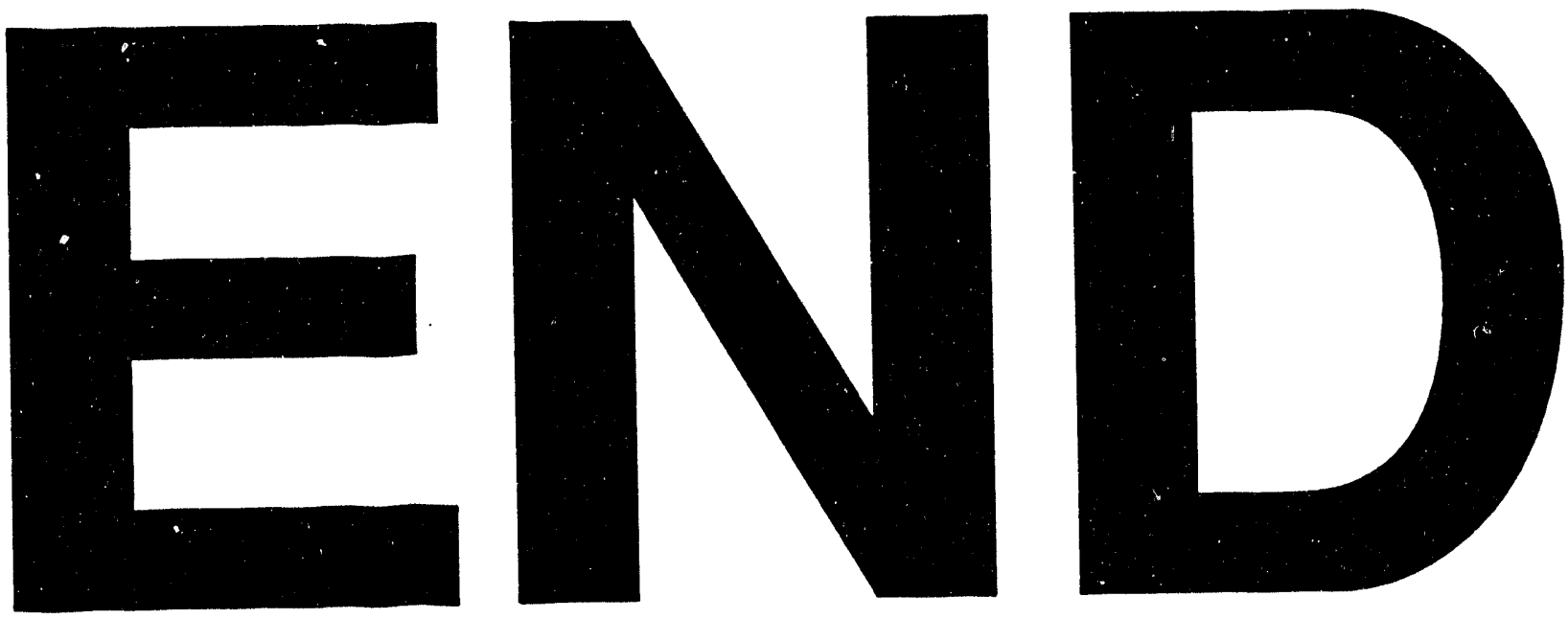


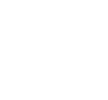

.
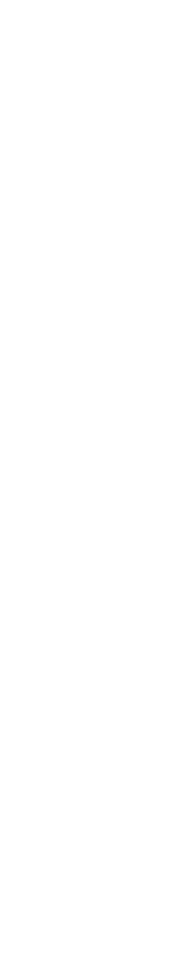

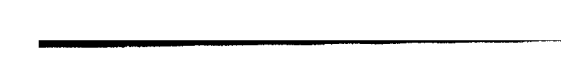

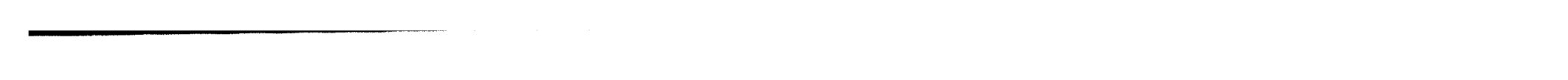

